\title{
Development and Research of Multifrequency X-ray Tube with a Field Nanocathode
}

\author{
T.A. Gryazneva, G.D. Demin, M.A. Makhiboroda, N.A. Djuzhev \\ and V.E. Skvorcov
}

\begin{abstract}
The conceptual model of X-ray source, consisting of the field-emission cathode and transmission-type thin film target, which is combined with X-ray transparent window, has been proposed. By means of numerical simulation methods, it was shown that the proposed design makes it possible to generate X-rays under the influence of an electron beam of the field-emission cathode. It is possible to get a small focal spot on the target and, therefore, a high resolution. The experimental sample of X-ray source was made and its measurement tests were conducted. The following results of the experimental studies of the sample of X-ray source were obtained: the power supply voltage is $37 \mathrm{kV}$, the power consumption is $2.77 \mathrm{~W}$, the cathode current is $74.80 \mathrm{~mA}$, the sample dimensions are $65 \times 22 \mathrm{~mm}$, the focal spot size is $439 \mathrm{~mm}$, and the cathode current is about $75.2 \mu \mathrm{A}$ after exposure to high and low temperatures.
\end{abstract}

Keywords X-ray source $\cdot$ X-ray $\cdot$ Field nanocathode $\cdot$ Autoemission Emission current · MEMS · Computer modeling

T.A. Gryazneva · G.D. Demin · M.A. Makhiboroda $(\bowtie)$

Science-Technology Center «Nano- and Microsystem Technique», National Research University of Electronic Technology «MIEE», Moscow, Russia

e-mail: m.makhiboroda@gmail.com

T.A. Gryazneva

e-mail: gryazneva@ntc-nmst.ru

G.D. Demin

e-mail: demin@ntc-nmst.ru

N.A. Djuzhev

Science-Technology Center «Nano- and Microsystem Technique», Multi-Access Center «Microsystem Technology and Electronic Component Base», Moscow, Russia

e-mail:djuzhev@unicm.ru

V.E. Skvorcov

LLC «MELZ», Moscow, Russia

e-mail: melz-zap@mail.ru

(C) The Author(s) 2018

K.V. Anisimov et al. (eds.), Proceedings of the Scientific-Practical Conference

"Research and Development - 2016", https://doi.org/10.1007/978-3-319-62870-7_45 


\section{Development of Mathematical Models and Numerical Experiment}

In this paper, the concept of the X-ray source is presented where the X-ray source consists of an array of field-electron emitters separated by a vacuum gap from the transmission-type thin-film metal target which is formed on the silicon membrane and operates as an X-ray window. The mathematical models of nano-sized cathode, transmission-type thin film target and silicon X-ray window, were developed. The simulation was conducted using software package COMSOL Multiphysics [1], based on which the important results were obtained needed for the optimization and further development of multifrequency X-ray tube.

In the proposed concept of X-ray source, the array of needle-type field-electron emitters with the tip radius of a few nanometers acts as a field-emission cathode [2, p. 37]. The control grid electrode general for the field-emitter array is made of a thin metal film with self-alignment holes opposite to each emitter, and it is isolated from the field-electron emitters by dielectric layer. Such an array of field emission units can be technologically realized based on silicon MEMS technology. X-window represents a square silicon membrane formed on the wafer by anisotropic etching, with the membrane's side length of $2 \mathrm{~mm}$. Thin metal film, which is deposited on the inner surface of membrane, is used as a transmission-type target. Schematically, the proposed model is shown in Fig. 1.

Fig. 1 The investigated conceptual model of the X-ray source

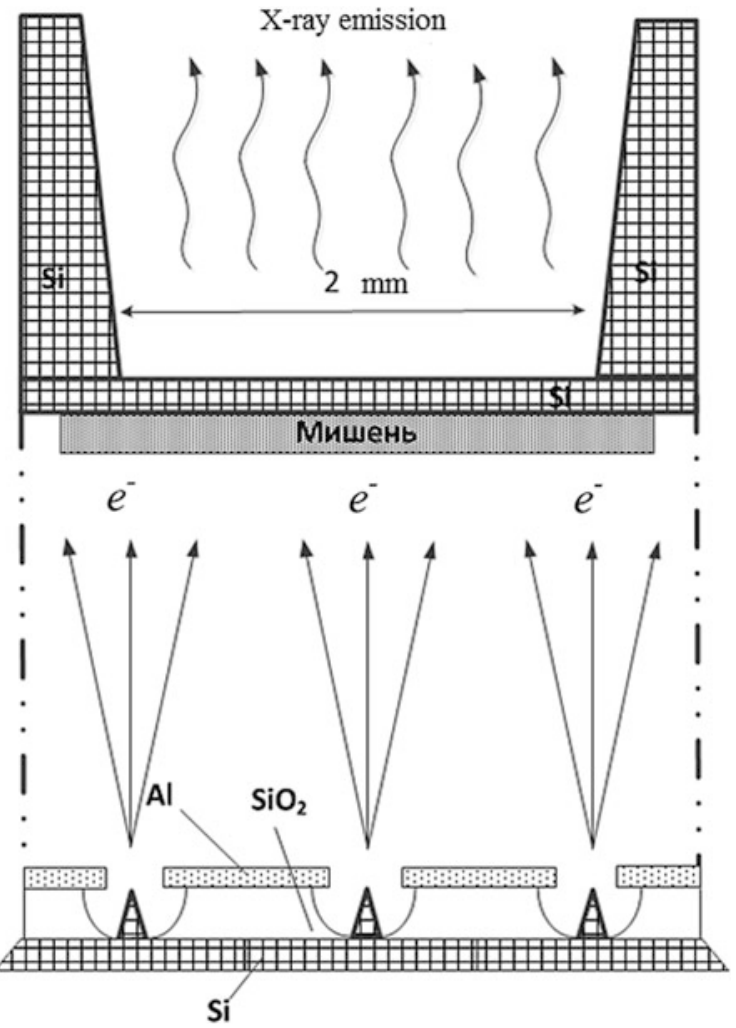


The proposed form of nanocathode is shown in Fig. 2. The main elements are silicon substrate with the array of tips formed thereon, the insulating dielectric layer, and metal film of the control grid electrode.

The geometrical dimensions of the cathode are shown in Table 1 .

During numerical experiments, voltages applied to the system were varied as follows: for the grid electrode the potential varies from 100 to $150 \mathrm{~V}$, and for the transmission-type target-from 0 to $40 \mathrm{kV}$ correspondingly. It was found that a detectable current occurs when the voltage on the control grid electrode is $100 \mathrm{~V}$, and it reaches value of about $90 \mathrm{nA}$ at $150 \mathrm{~V}$. Therefore, to ensure the total emission current of $75 \mathrm{~mA}$, an array of $\sim 850$ nanocathodes is required. Since the linear dimensions of the single nanocathode is less than $10 \mu \mathrm{m}$, the allocation of that amount of cathodes within a small area is technically achievable task.

Tungsten W $(Z=74)$ and molybdenum Mo $(Z=42)$ were chosen as target materials. Trajectories of electrons that penetrate into the target material at a beam energy of $40 \mathrm{keV}$ were calculated based on the Monte Carlo simulation using Win $\mathrm{X}$-ray software [3, p. 1498].

It was found that the effective generation of radiation is achieved in the tungsten film with the thickness of $0.25 \mu \mathrm{m}$ and in molybdenum film with the thickness of $0.13 \mu \mathrm{m}$, respectively. Experimental measurements have shown that the $1-\mu \mathrm{m}$ thickness silicon membrane with dimensions of $1 \times 1 \mathrm{~mm}$ can withstand pressure more than 2 atmospheres. Thus, the silicon membrane of $1-\mu \mathrm{m}$ thickness provides not only sufficient transparency for X-rays generated by the target of almost all types of materials but also has a required mechanical strength.

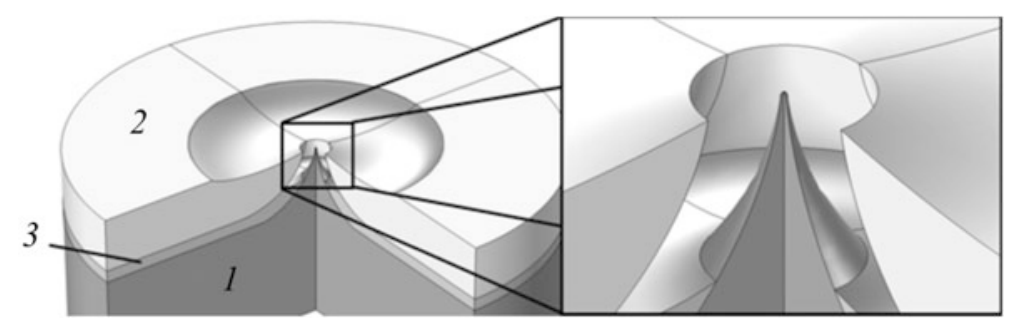

Fig. 2 Structure of nanocathode. 1 silicon (substrate); 2 metal grid electrode; 3 dielectric insulating layer

Table 1 The main dimensions of the elements of nanocathode

\begin{tabular}{l|l}
\hline Characteristic & Value \\
\hline Spherical radius of tip & $10 \mathrm{~nm}$ \\
\hline Radius of the hole in the grid electrode & $4.5 \mu \mathrm{m}$ \\
\hline Height of tip & $1 \mu \mathrm{m}$ \\
\hline The thickness of dielectric layer & $0.2 \mu \mathrm{m}$ \\
\hline The thickness of the electrode film & $0.9 \mu \mathrm{m}$ \\
\hline The distance between the cathode tip and target & $5 \mathrm{~mm}$ \\
\hline
\end{tabular}




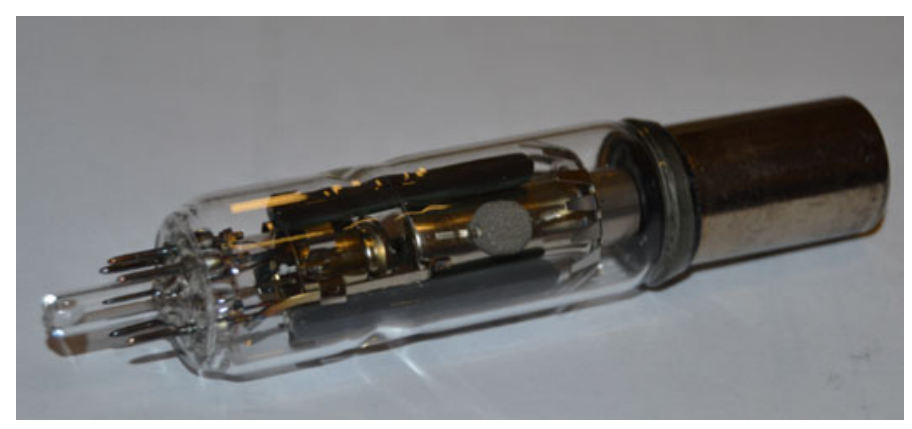

Fig. 3 Experimental sample of X-ray source

Table 2 Specifications of $\mathrm{X}$-ray source

\begin{tabular}{l|l}
\hline Operating voltage & From 30 to $40 \mathrm{kV}$ \\
\hline Power consumption & Less than $3 \mathrm{~W}$ \\
\hline Cathode current & $75 \pm 5 \mathrm{uA}$ \\
\hline Size of focal spot & Less than $500 \mu \mathrm{m}$ \\
\hline Operating temperature range & From -40 to $+85^{\circ} \mathrm{C}$ \\
\hline Overall dimensions & $70 \pm 2 \times 20 \pm 2 \mathrm{~mm}$ \\
\hline
\end{tabular}

\section{Preparation of Experimental Sample of X-ray Source}

With the assistance of industrial partner of the project, Limited Liability Company "MELZ", an experimental sample of X-ray source was made using solutions developed in our research.

Experimental sample of X-ray source is presented in Fig. 3 the working characteristics of which are summarized in Table 2.

\section{Experimental Results}

For experimental research of test samples of field nanocathode and the sample of X-ray source special stands were fabricated (Fig. 4).

During the experimental research of the samples of nanocathode, the threshold voltage required for the field emission (the level of the detectable current $\sim 10 \mathrm{nA}$ ) was 20-25 V at the initial state, and it was decreased after a short measurement test to less than $20 \mathrm{~V}$. Thus, the measured values of current from a single cathode are more than $1.5 \mathrm{~mA}$, which corresponds to a current density of about $5-10^{5} \mathrm{~A} / \mathrm{cm}^{2}$. Such current density of field-electron emission is considered to be very high for the operation of the emitter in a static mode and lies on the boundary of the current range, in which significant heating and degradation of the emitters occur [4, p. 22; 5, p. 387].

The following results from the experimental research of the fabricated sample of X-ray source were obtained: the power supply voltage is $37 \mathrm{kV}$, the power 
Fig. 4 Stands for the experimental research: Left part of the photo is for X-ray source, Right part of the photo is for Cathode

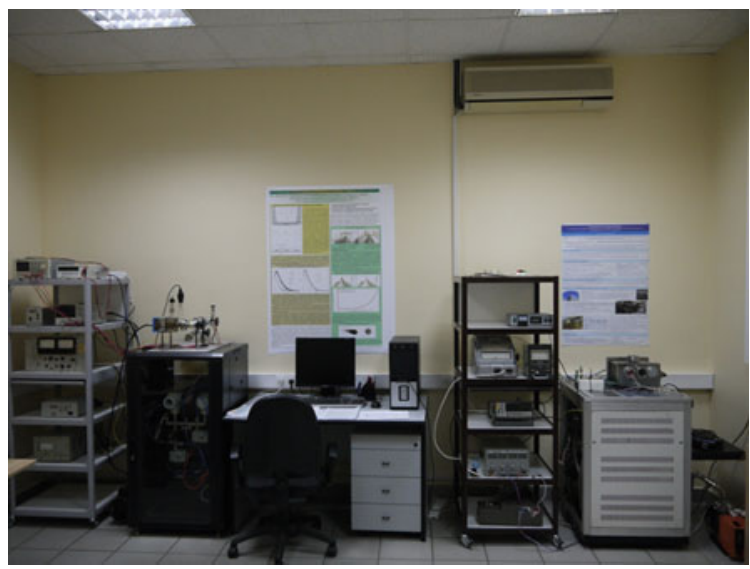

consumption is $2.77 \mathrm{~W}$, the cathode current is $74.80 \mu \mathrm{A}$, the sample dimensions is of $65 \mathrm{~mm} \times 22 \mathrm{~mm}$, the focal spot size is $439 \mu \mathrm{m}$, and the cathode current is about $75.2 \mu \mathrm{A}$ after exposure to high and low temperatures.

\section{The Potential Practical Application of Research Results}

At the present time in various fields of science and technology there is an urgent need for the miniature X-ray source with low power consumption and the possibility of adjustment of radiation frequency. Such X-ray sources are in demand in a number of practical applications, such as medical technology, scientific analytical equipment, security systems and counter-terrorism systems. X-ray sources, providing a focal spot and resolution in the nanometer range, will find applications in advanced analytical equipment and technologies for the fabrication of nanostructures and new materials.

Electron and scanning probe microscopy allows mainly obtaining an image of the surface of objects, but in many respects the properties of nanomaterials are related to their internal structure.

Information about the internal structure can be obtained only with special preparation of samples such as cleavage of sample or preparation of microscopic section. Furthermore, with layer-by-layer ion beam etching of the surface, it is possible to obtain this kind of information about the objects under study. But these are destructive and expensive methods do not give full and online information about the nanomaterial. There are a number of problems with the preparation of facilities to conduct such studies, as well as with and interpretation of the results. By means of the X-ray radiation it is possible to examine the internal structure of the objects and to obtain three-dimensional images. This radiated emission practically does not interact with the objects and in many cases does not require special preparation of samples. Research can be done in the air, including a liquid phase, and in a vacuum. 
In addition, at the present time research is being conducted by the combination of local exposure of the substrate to the radiation of the X-ray source and processes of ALD for the realization of additive technologies (3D printing) for the formation of topological elements of the functional layers depending on the type of reactive chemical, surface, and the wavelength of the emission.

\section{Conclusion}

As a part of the research and development of multifrequency X-ray tube with a field nanocathode, there was developed a mathematical model of nanocathode, transmission-type thin film target, and silicon X-ray window. Simulation was performed and results were obtained, which show the fundamental performance of the proposed concept. The combination of field emission cathode as a source for narrow electron beam, electron optics, and transmission-type thin film target, combined with a silicon X-ray window, opens the possibility of creating a new class of devices - scanning and multifrequency microfocus X-ray sources.

Acknowledgements Research is conducted with the financial support of the Ministry of Education and Science of the Russian Federation. Agreement No 14.578.21.0001 (RFMEFI57814X0001).

\section{References}

1. Comsol MultiPhysics [Electronic resource] URL:http://www.comsol.ru

2. Dyuzhev, N.A., Makhiboroda, M.A., Gusym, E.E., Gryazneva, T.A., Demin, G.D.: The process flow simulation of the cathode-grid system and its emission properties. Problems of development of perspective micro and nanoelectronic systems-2016. Collected works under the General editorship of academician RAS A.L.Stempovskogo, M., Part IV. pp. 37-42. (in Russia) (2016)

3. Demers, H., Horny, P., Gauvin, R., Lifshin, E.: Microsc. Microanal. 8(S02), 1498 (2002)

4. Dyuzhev, N.A., Makhiboroda, M.A.: Mathematical modeling of heat processes involved in field emission of nano-sized tip. In: Proceedings of universities. Electronics, No 2(88), pp. 22-26. Russia (2011)

5. Dyuzhev, N.A., Makhiboroda, M.A., Kretov, V.I., Churilin, M.N., Rudnev, V.Y.: Investigation of the thermal degradation of the silicon field-emission cathode as a two-phase system. Russian Microelectron. 41(7), 387-392 (in Russia) (2012) 
Open Access This chapter is licensed under the terms of the Creative Commons Attribution 4.0 International License (http://creativecommons.org/licenses/by/4.0/), which permits use, sharing, adaptation, distribution and reproduction in any medium or format, as long as you give appropriate credit to the original author(s) and the source, provide a link to the Creative Commons license and indicate if changes were made.

The images or other third party material in this chapter are included in the chapter's Creative Commons license, unless indicated otherwise in a credit line to the material. If material is not included in the chapter's Creative Commons license and your intended use is not permitted by statutory regulation or exceeds the permitted use, you will need to obtain permission directly from the copyright holder.

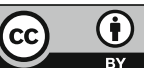

